\title{
Repurposing the past? The historical basset clarinet in creative collaboration
}

Emily Payne*

School of Music, University of Leeds, Leeds, UK

In this article I examine the role of the instrument in Evan Johnson and Carl Rosman's

collaboration on a new work for eighteenth-century basset clarinet, 'indolentiae ars', a medium to be kept (2015). Drawing on material collected over 30 months - including interviews; audio-visual footage; and correspondence containing sketches, fingering charts, and recordings - I consider the latent practices that lie within the instrument, and their role in the creative process. From the aesthetic discourses that pervaded the musicians' discussions, to the transitional and sometimes 'accidental' moments of instrumental interaction during workshops, I trace the micro-processes within the broader creative trajectory, in order to understand how the instrument's historical, social, and ergonomic affordances were enmeshed within the here-and-now of the collaboration. The article illustrates the dynamic character of collaborative work, shaped not solely by the knowledge of individuals, but through a close reciprocity between perception, action, and the discursive and material conditions of their surroundings.

Keywords: clarinet, composer-performer collaboration, creativity, historical instrument, workshop

\footnotetext{
*Email: e.1.payne@leeds.ac.uk
} 


\section{Repurposing the past? The historical basset clarinet in creative collaboration}

In his dedication to 'indolentiae ars', a medium to be kept for eighteenth-century basset clarinet (2015), Evan Johnson emphasises the significance of the contribution made to the piece by its performer, Carl Rosman. He writes:

This piece is tailored in every possible way to Carl Rosman: his unusual instrument and his explorations upon it (and therefore his multiphonics, his fingerings, his microtones), his transcendent virtuosity, his penetrating intellect, his tolerance of ambiguity, his immersion in musical history, his voice, his stage presence, his control of silence, even his page-turning technology. In gratitude for almost ten years of a relationship that has become one of the foundations of my musical life: nothing I've ever done has been dedicated so profoundly. (Johnson, 2015, p. i)

Commissioned by the Cologne-based ensemble musikFabrik and premiered by Rosman in February 2016, the piece is the outcome of two years' close work between the two musicians, as well as a longer professional relationship and rapport, to which Johnson alludes above. ${ }^{1}$ Indeed, 'indolentiae ars' is a distillation of a sufficiently significant collaborative attunement such that Johnson acknowledged that it might never be performed by another musician:

Unless I wind up making a version for a modern instrument (which I may or may not do), it will be absolutely for the combination of Carl and this particular instrument - nobody else will ever play it - and, from his end, it involves developing a technique, creating a relationship with an instrument, that will likely be useful primarily for this one piece, even if there turn out to be others written for the instrument. (E. Johnson, unpublished email correspondence to E. Payne, 15 April 2014.)

'Creating a relationship with an instrument', as Johnson puts it, is the focus of this article, in which I examine the processes through which new practices and musical materials were developed over the course of the commission, in order to explore questions relating to musician-instrument interaction and their role in joint creative work.

Johnson and Rosman's decision to employ a historical basset clarinet meant that there was much about this collaboration that was unprecedented. The instrument was made by the 
Dutch instrument maker Peter van der Poel, and is based on a design by Theodor Lotz (17471792), the Viennese maker who is directly associated with Anton Stadler, the clarinettist for whom Mozart wrote his Concerto K. 622 (1791) and Quintet K. 581 (1789) (Poulin, 1991). This is the first contemporary commission written for the instrument, whose extant solo repertoire is limited to that of Mozart. ${ }^{2}$ Moreover, while Rosman has a reputation as an internationally leading performer of new music, he had never performed on this instrument in public before this project, commenting at the first workshop that 'I'm not quite there yet with it to do something beyond just playing it to myself' (Workshop 1, 4 April 2014). Thus, a significant aspect of the collaboration between composer and performer was the development of a new instrumental rhetoric and forms of notation with this distinctive and initially somewhat unfamiliar instrument.

I examine the formation of compositional material from three angles: the wider historical and cultural dimensions of the creative ecology; the development of techniques through various categories of engaged interaction; and Rosman's embodied relationship to his instrument and his developing technical expertise in preparing for performance. The structure of the discussion moves from the broad to the specific, from the wider aesthetic discourses that pervade the collaboration to the momentary and in some cases 'accidental' outcomes that occur as a result of a specific interplay between body and instrument. In this way, I trace the micro processes within the larger collaborative trajectory, in order to understand how the particular historical, social, and ergonomic affordances of the instrument were enmeshed within the here-and-now of the present collaboration. The article illustrates the dynamic character of collaborative work, shaped not solely by the knowledge of individuals, but through a close reciprocity between perception, action, and the discursive and material conditions of their surroundings. Ultimately, I make the case for performance practices being co-produced by an interplay between performers and the complex 'musical 
ecosystems' (Clarke, Doffman, \& Lim, 2013, p. 628) - and consisting of people, objects, histories, and processes - which they inhabit.

Johnson and Rosman's commission forms a case study of a larger research project investigating the creative processes of performance by documenting professional clarinettists and composers working together in various collaborative contexts (Payne, 2015). Employing a similar methodological approach to other recent studies of 'real-world' contexts of Western 'concert' musics (see, among others, Bayley, 2010, 2011; Bayley \& Clarke, 2009, 2011; Clarke, Cook, Harrison, \& Thomas, 2005; Clarke et al., 2013; Clarke, Doffman, \& Timmers, 2016; Donin \& Féron, 2012; Donin \& Theureau, 2007), the material on which this paper is based was collected over a 30-month period (November 2013-February 2016) and includes interviews with Johnson and Rosman conducted at various stages during the process; audiovisual footage of workshop meetings, ${ }^{3}$ rehearsals, and the premiere; in addition to email correspondence of c. 14,000 words, including audio recordings of techniques and passages, sketch materials, and score fragments (see Table 1 for a summary of the audio-visual material collected during fieldwork).

Table 1. List of audio-visual material. Personnel are CR (Carl Rosman), EJ (Evan Johnson), and EP (Emily Payne).

\begin{tabular}{|l|l|l|l|}
\hline Location and date & Event & Personnel & Data \\
\hline $\begin{array}{l}\text { Huddersfield, 9 } \\
\text { November 2013 }\end{array}$ & Semi-structured interview & CR, EP & Audio only \\
\hline $\begin{array}{l}\text { Cologne, 4 April } \\
2014\end{array}$ & Workshop 1 & CR, EJ, EP & Audio-visual \\
\hline $\begin{array}{l}\text { Cologne, 6 April } \\
2014\end{array}$ & Semi-structured interview & EJ, EP & Audio only \\
\hline $\begin{array}{l}\text { Darmstadt, 3 } \\
\text { August 2014 }\end{array}$ & Workshop 2 & CR, EJ, EP & Audio-visual \\
\hline $\begin{array}{l}\text { Cologne, 1 } \\
\text { December 2014 }\end{array}$ & Workshop 3 & CR, EJ & Audio only \\
\hline
\end{tabular}




\begin{tabular}{|l|l|l|l|}
\hline $\begin{array}{l}\text { Cologne, } 8 \\
\text { February 2016 }\end{array}$ & Complete run-through & CR & Audio only \\
\hline $\begin{array}{l}\text { Cologne, } 14 \\
\text { February 2016 }\end{array}$ & Rehearsal & CR, EJ, EP & Audio-visual \\
\hline $\begin{array}{l}\text { Cologne, 15 } \\
\text { February 2016 }\end{array}$ & Sound check and rehearsal & CR, EJ, EP & Audio only \\
\hline $\begin{array}{l}\text { Cologne, 15 } \\
\text { February 2016 }\end{array}$ & Premiere & $\begin{array}{l}\text { CR, EJ, EP, } \\
\text { audience }\end{array}$ & Audio-visual \\
\hline $\begin{array}{l}\text { Skype, 16 March } \\
2016\end{array}$ & $\begin{array}{l}\text { Semi-structured group } \\
\text { interview }\end{array}$ & CR, EJ, EP & Audio only \\
\hline
\end{tabular}

The first workshop took place in Cologne in April 2014, and was followed by two subsequent workshops, one during the Darmstadt Summer Course for New Music in August 2014 and one in Cologne in December of the same year. I attended and filmed the first two workshops, and the participants made and shared with me an audio recording of the third. Since there is a considerable distance geographically between composer and performer (Johnson is based in Massachusetts and Rosman lives in Cologne) they pursued a regular and detailed email correspondence over the course of the project, culminating with Johnson sending Rosman a 'complete' score in June 2015. Rosman recorded a complete run-through of the piece and sent it to Johnson on 8 February 2016, ahead of the rehearsals and premiere that took place at the musikFabrik Studio in Cologne the following week. The concert was recorded and will be released on Label musikFabrik.

\section{Locating the instrument in creative collaboration}

This special issue on the subject of collaboration in contemporary music is indicative of a recent but rapidly expanding body of research addressing joint creative work in composition and performance. Over the past decade investigations of composer-performer interactions have flourished, whether addressing the face-to-face encounters between performers and composers during the genesis of a work (Clarke et al., 2016; Donin \& Féron, 2012; Donin \& 
Theureau, 2007; Fitch \& Heyde, 2007; Hayden \& Windsor, 2007; Kanga, 2014; Östersjö, 2008); and/or composer-performer(s) interplay and negotiation during rehearsal (Archbold, 2011; Barrett et al., 2014; Bayley, 2010, 2011; Bayley \& Clarke, 2009, 2011; Clarke et al., 2013; Seddon, 2004; Seddon \& Biasutti, 2009). A small corpus of work has evaluated the composer-performer relationship from the perspective of the clarinettist, addressing a variety of questions including the socio-psychological effects of engaging with composers on the performer's creative practice (Roe, 2007); the expediency and contingency of the collaborative process, and the influence of external factors and other creative agents such as conductors, recording engineers, and producers (Merrick, 2009); and the role of dialogue in collaboration (Roche, 2011). While these studies provide detailed accounts of performerresearcher practices and are rich in terms of their artistic outputs, the instrument is often treated as an apparently passive object within the creative process.

Looking beyond the clarinet, a small number of studies have addressed the role of the instrument within collaborative work. In their auto-ethnographic account of working together on a new commission for speaking cellist, Fabrice Fitch and Neil Heyde (2007) draw on Helmut Lachenmann's (1996) metaphor of composition as 'building an instrument' (Fitch \& Heyde, 2007, p. 92) to capture the gradual tuning, or integration, of the performer and instrument, evident in a figurative sense in relation to the new instrumental techniques and sonorities that the musicians develop; and in one particular instance - the specialised execution of scordatura - quite literally. The final composition is tightly intertwined with Heyde's own performance idiom to such an extent that Fitch concludes that from his perspective, and echoing Johnson's dedication above, 'there is no doubt that the piece in its final form would be unthinkable without the input of this particular performer' (p. 93). Engaging with his practice as a classical guitarist working with composers on a series of new performance projects, Stefan Östersjö's (2008) relationship with his instrument appears to be 
as significant as his relationship with his fellow collaborators, and in a statement that sums up the complex interrelations that shape his experience as a performer, he writes:

[I]t is not possible to separate my critical reflections on my own practice as a performer from issues of the musical work, musical interpretation, authenticity and intention, nor from the influence of an absent or present composer, from technology, my instruments, the score and other 'texts'. (2008, p. 27)

Writing from the perspective of researcher rather than performer, Michael Hooper's (2012) examination of the oboist Christopher Redgate's collaborations with the composers Dorothy Ker and Fabrice Fitch employing the redesigned 'Redgate-Howarth' system oboe (see Hooper, 2013; Redgate, 2007), identifies the instrument as a potentially powerful 'agent' within composer-performer collaboration, and deconstructs the traditional understanding of the performer's relationship with his or her instrument. Hooper's conclusion hints at a sense of the relational and distributed processes at play in 'a wide collaborative network that includes [the composer], Redgate, an oboe, works in the oboe's repertory, past practice, obsolete mechanism, new keywork and much else besides' (Hooper, 2012, p. 36). Rather than a 'network', Clarke et al. (2016) have suggested that this more complex and fluid relationship might best be understood as an 'ecological mesh' (p. 121; see also Clarke et al., 2013; Ingold, 2011). Their study of the interactions between violinist (Peter Sheppard Skærved) and composer (Jeremy Thurlow) in the creation, preparation, and performances of Ouija for solo violin and electronics (2013) demonstrates how Sheppard Skærved's embodied engagement with his particular instrument, a Stradivarius once owned by Joseph Joachim, is of fundamental importance to his relationship with his sound, his co-performers, and the audience. In this way, the authors argue, 'the instrument and body [...] act as a repository of history' (p. 157).

The concept of an instrument as a 'repository' echoes the anthropologist Edwin Hutchins' (1995) account of distributed cognition in the navigation of a US Navy vessel, in 
which he describes the ship's tools as 'repositories of knowledge [...] constructed in durable media so that a single artifact might come to represent more than any individual could know' (Hutchins, 1995, p. 96). There have been few empirical investigations of distributed cognition in musical performance, ${ }^{4}$ but Jonathan de Souza (2013) has applied Hutchins' work to investigate the relationship between performer and instrument. He writes:

The interaction of body and instrument - with all its cognitive consequences - is an interaction of individual and culture, of the present and the past. Instrumental mediation engenders cultural learning beginning from the haptic level of physical skill. Instruments, in other words, ground modes of music cognition that are embodied, technically conditioned, and historically situated. (de Souza, 2013, p. 50)

De Souza's interests ultimately lie elsewhere, in the relationship between the performer's body and instrument rather than the distribution of knowledge during co-present collaboration, yet in drawing attention to instruments' physical, technical, and historical affordances, he offers a fruitful framework for approaching the basset clarinet in this project, which, like Sheppard Skærved's violin, has powerful historical and cultural resonances. Thus, attending to the social life of musical instruments (see Appadurai, 1988; and Bates, 2012) in collaborative work may offer an opportunity to delve more deeply into the processes of music-making that might otherwise be overlooked. It is to the instrument, and its role in Johnson and Rosman's collaboration that I turn now.

\section{The historical basset clarinet}




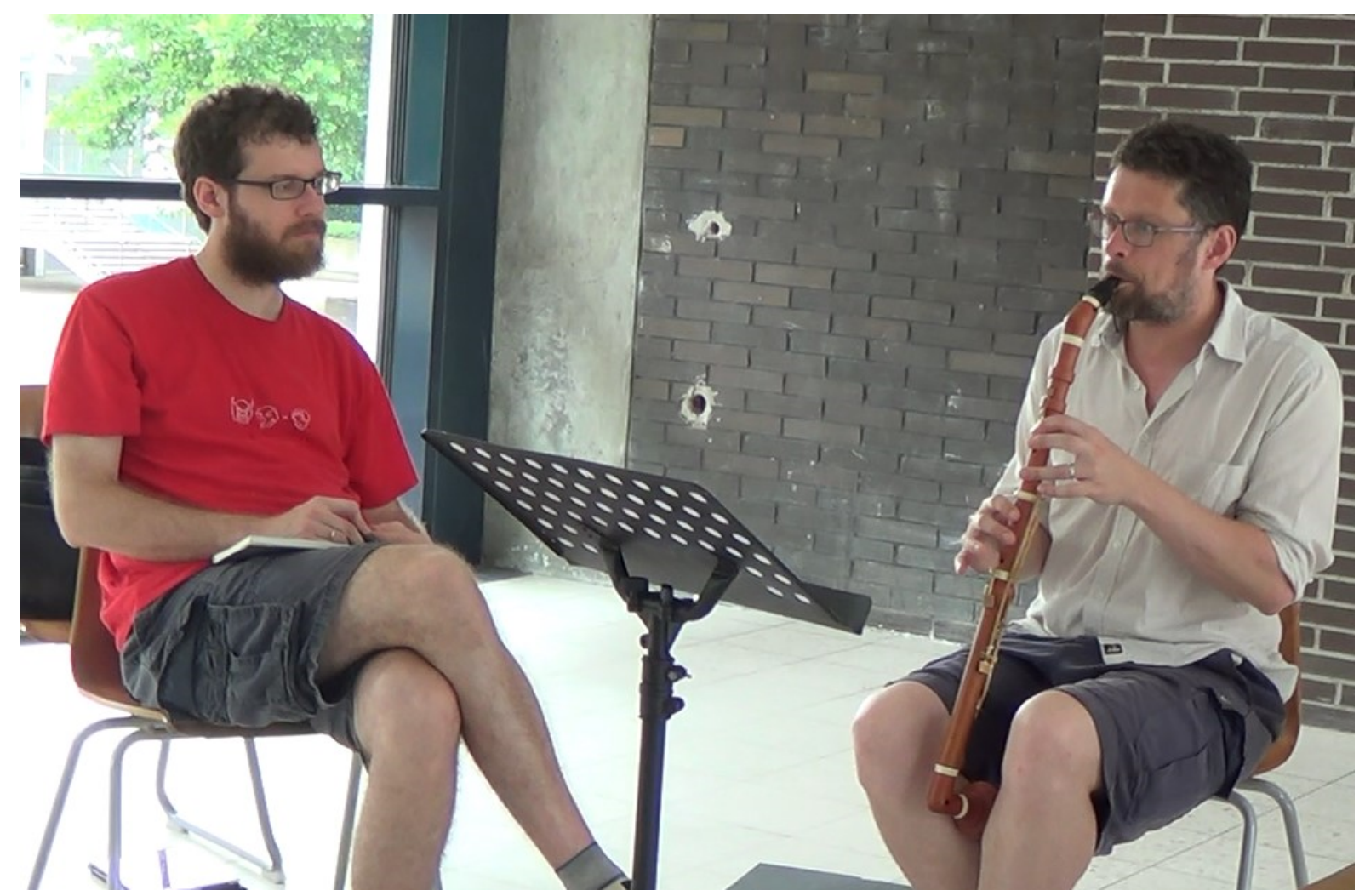

Figure 1. Video still from Workshop 2, 3 August 2014.

As is clear from the image above, the historical basset clarinet bears very little resemblance to its modern counterpart, possessing a number of properties that are distinct from the 'standard' modern model. ${ }^{5}$ It is constructed from boxwood rather than the grenadilla that is commonly used today, and as a consequence it is much lighter - in both colour and weight. The mouthpiece is narrower, and requires smaller and softer reeds. It has a wide bore, with larger tone holes that are positioned lower down the instrument, particularly those of the right hand (van der Poel, 2014). The B2 is executed by covering an open hole located on the 'knee' joint, usually with the performer's leg. In contrast to the modern clarinet, which can have in the region of seventeen to twenty-two keys in addition to four to seven ring keys, the basset clarinet usually has nine keys, of which four operate the lower 'basset' notes. This minimal mechanical system, with keys that operate independently from one another, has a number of consequences for the performer. On the one hand, the lack of fully chromatic keywork presents ergonomic constraints in that cross-fingerings and half-hole fingerings must be 
employed. ${ }^{6}$ Intonation is extremely variable: tuning the $\mathrm{B} \sharp 3$ is problematic, for example, as it is approximately a quartertone flat, requiring a half-hole fingering and change of embouchure to adjust the pitch. On the other hand, the open tone holes and lack of linkage between keys means that many more fingering configurations are possible, affording huge flexibility of colour. As well as its powerful historical significance, the instrument clearly offers a large number of possibilities in relation to harmonic and timbral material - the question is the extent to which, and the manner in which, they were explored within the collaboration.

Johnson describes his music as being concerned with 'physical and bodily underpinnings of performance' (Johnson, 2014), a point he elaborated on during interview:

With a lot of my work, I aim for this result which is this very gentle, very delicate, very lyrical almost, ornamented, graceful thing, but (especially in solo pieces) I like to try and get there through ways that take a lot of energy. So things that barely sound that the instrument has to force out and you get a little squeak at the end; or things that are just really awkward or really tiring to do but generate these really soft and gentle results. So I'm really interested in those things that require the sense of the body, the sense of the musculature and the embouchure and the lungs, but completely privately. (E. Johnson, unpublished interview, 6 April 2014)

A performer of Johnson's music is often pushed to an extreme position, but in a manner that might not necessarily be conveyed to the audience - the material that he writes is less about eliciting a specific sounding result than setting up a particular circumstance of performative ambiguity. We can begin to see why the basset clarinet, with its inherent instabilities, fragilities, and inconsistencies, might be particularly attractive to him.

Given the specificity of the basset clarinet's design, Johnson was reliant upon the technical expertise of Rosman during the workshop stage in order to create a relationship with an unfamiliar instrument and performance practice. Part of Rosman's role was to share with Johnson a sense of his embodied relationship with the instrument to such an extent that he was able to compose for the instrument, but not so much that he would ever perform with 
it. Equally, Rosman was obliged to interrogate his individual performance practices in order to develop a performance practice that is heavily intertwined with this instrument and the specific performance circumstances of their collaboration. This meant that their creative relationship was arguably symbiotic: as Rosman's technique developed he was able to share his increasing proficiency with Johnson, which in turn enabled Johnson to explore new aesthetic avenues during their workshops. In this collaboration then, the development of knowledge can be observed as distributed across the interactions of performer, composer, and instrument - and importantly, is crucial to their creative agency.

\section{Developing a new instrumental rhetoric}

With this background in mind, the following discussion focuses on three instances of the development of new musical material. A key question at the outset of the project was the extent to which the basset clarinet's historical lineage might play a role in the creative process. Or, as Johnson put it, 'To what degree is this just an exotic quasi-clarinet, and to what degree is it a specifically eighteenth-century instrument?' (E. Johnson, unpublished email correspondence to E. Payne, 15 April 2014; original emphasis). Repurposing a historical instrument in a contemporary context engenders a certain sense of cultural baggage, or what Johnson and Rosman initially described as 'the Mozart problem' (Workshop 1, 4 April 2014): the weight of composing for an instrument that is so strongly associated with a single composer and in particular, with two of his most prominent works. While Johnson acknowledged the significance of the instrument's historical context, he was keen to avoid drawing on it in too obvious a manner, commenting:

It's certainly not going to be based on Mozart and any sort of quote, but it' $\mathrm{d}$ be sort of a shame not to have some thought given to that. [...] It would be nice to have a special thing that somehow implicitly addresses the historical context in some sense. [...] It would not surprise me if there's some sort of idea of Mozartian gesture or ornamental practice or scales or something that wound up somehow, hopefully subtly. I'm really allergic to pastiche. (E. Johnson, unpublished interview, 6 April 2014) 
Nevertheless, when asked during the first workshop whether it was possible to approach the basset clarinet in isolation from Mozart, Rosman replied: 'Not for me! [...] With this [instrument] it is very clear that Mozart or Mozart-type music just fits it' (Workshop 1, 4 April 2014). As well as the instrument's aesthetic signifiers, Mozart's music was also impressed upon Rosman's embodied relationship to the instrument, since at the outset of the project his practice routine consisted largely of working on the extant repertoire - the Concerto and Quintet; and, throughout the workshops he played sections from, and improvised with, material from those two pieces.

\section{The invention of multiphonics}

A striking compositional feature of 'indolentiae ars' is Johnson's use of multiphonics, which breaks new ground in two ways. First, as Rosman observed, 'this might well be the first time multiphonics have been specifically written for this instrument, or perhaps even at all for a historical clarinet' (C. Rosman, unpublished email correspondence to E. Johnson and E. Payne, 22 May 2015); and second, this is the first time that Johnson has employed multiphonics in a significant way in his music. ${ }^{7}$ He explained:

I don't tend to use multiphonics that way because my approach isn't at all about 'Here, listen to this sound, let's linger with it and admire it...' but rather there are always so many things going on, constantly compromising each other, that the sort of 'framing' you often need to get a multiphonic doesn't work with what I'm trying to do. (E. Johnson, unpublished email correspondence to C. Rosman and E. Payne, 20 May 2015)

'indolentiae ars' contains multiphonics in various incarnations: dyads and triads resulting from cross-fingerings. At a later stage of the project, Johnson asserted that a motivating factor for employing multiphonics in a significant manner in this piece was his desire to take advantage as much as possible of the material properties of the basset clarinet, and of Rosman's relationship to them. During the first workshop, however, although Rosman stated 
that microtones and multiphonics were the sounds about which he was most excited, multiphonics were not a significant topic of discussion, with Johnson responding 'I'm not really a multiphonic person' (Workshop 1, 4 April 2014). At one point during the workshop Rosman began to explain how the instrument's minimal keywork requires cross-fingerings to be employed, making the instrument more amenable to producing overtones and undertones, and thus multiphonics. He demonstrated to Johnson the fingering configurations used to bring out the upper harmonics of a multiphonic and offered to investigate them further, but Johnson appeared uninterested, stating 'In general I'm more interested in colour, microtonal fingerings and things that can be trilled' (Workshop 1, 4 April 2014).

In the second workshop, however, a discussion of the instrument's microtonal possibilities led to a more extended and participatory exchange, with Rosman exploring multiphonics in the clarino register in greater depth (see Video example 1). At the beginning, it is unclear which direction the interaction will take: the discussion of microtonal flexibility could have been pursued further, but it is Johnson's response to Rosman's demonstration ('It sounds like that's multiphonic territory') that directs it towards multiphonics. The relationship between verbal elaboration and practical exploration in this episode is balanced, with Johnson taking an active role in evaluating Rosman's playing. He seemed intrigued by the multiphonics, and particularly interested in undertones caused by a change of attack. The interaction during this episode has a sense of shared discovery, with Rosman also uncovering techniques that he had not encountered before ('That's a new one!'), and diagnosing ways of executing the sounds ('That's a kind of no-tongue attack'). The musicians' sense of engagement is apparent, with both of them apparently interested in the execution of the sounds, rather than the sounds themselves. Their conversation is also indicative of their familiarity with one another, with phrases such as Johnson's 'As you know...' and Rosman's statement 'Except of course that these are not your kind of intervals.' By the end of this 
exchange Johnson is clearly more interested in multiphonic possibilities, particularly in terms of their potential to create volatility. In a subsequent email he explained the way in which he had integrated the technique within his personal compositional aesthetic:

I resolved not to [...] 'frame' these multiphonics as objects to admire - so that they sometimes occur in the midst of other things so that they may not sound properly, or not sound as written, and so forth - and even when there is more space around them temporally speaking they are often forced to coexist with trills, vocal actions, etc., that destabilize them in other ways. [...] Several multiphonics are labeled 'risk not sounding', 'not quite enough time', etc. [...] Also - and here's where my approach to the topic is more or less the same as everyone else's, I think - I tend to think of multiphonics as vectors of energy, as expressions of surplus, of forcing things out the 'cracks' of the instrument - so sometimes they are meant to have more 'energy' to them (in terms of harmonic content, dynamic range, etc.) than others. That also influenced what went where. (E. Johnson, unpublished email correspondence to C. Rosman and E. Payne, 20 May 2015)

The idea of multiphonics as symptomatic of excess energy, rather than solely a timbral effect, made them a valuable element to draw into Johnson's existing compositional rhetoric.

The lowered $\mathrm{G} \sharp 4$ / raised $\mathrm{B}, 4$ dyad demonstrated by Rosman during this episode subsequently took on a significant role in the architecture of the piece. Several months after this workshop, Johnson emailed Rosman to obtain a more detailed sense of the extent to which the multiphonic was easily accessible from other pitches, and its potential interactions within the wider context of the piece. Rosman responded by sending through the fingering chart and a recording of each multiphonic with a verbal commentary describing how each sound is best reached, whether from the upper or the lower note of the dyad (Audio example 1). Figure 2 is an extract from the fingering chart with the dyad highlighted. 


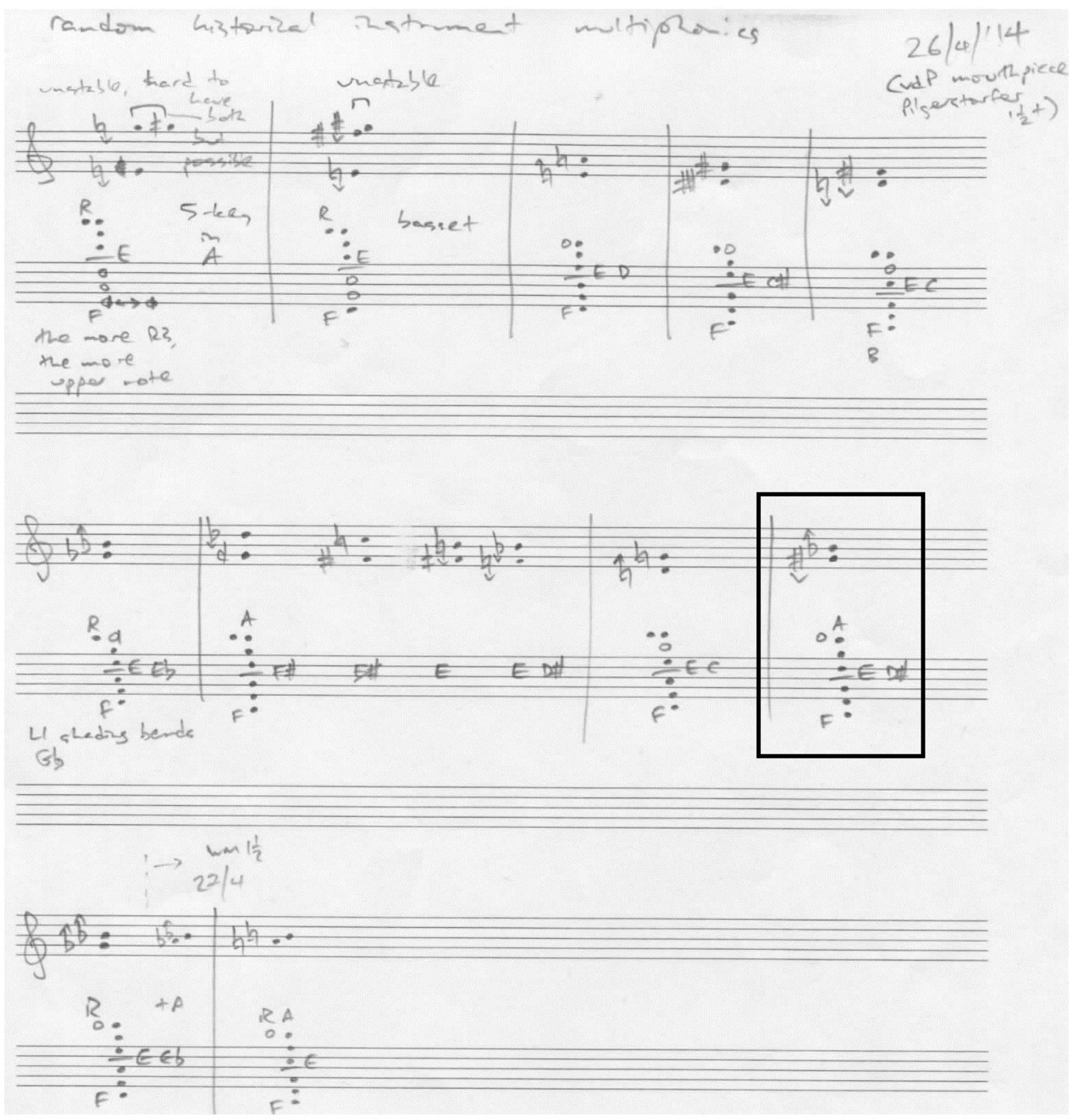

Figure 2. Extract from one of Rosman's multiphonic fingering charts (26 April 2014).

Reproduced by permission of C. Rosman.

Here Rosman has recorded several possible multiphonic sounds and their corresponding fingering pattern. ${ }^{8}$ Underneath the transcription of each sounding result he has provided a visual representation of the open and closed holes on the body of the instrument, with the letters indicating which keys should be depressed. This chart is a mapping of Rosman's technical relationship with the instrument at the initial stages of developing a performance practice. He used it to record the physical properties of each technique, for example, by 
noting an unstable interplay between two pitches, or to indicate that shading the first left hand finger bends the pitch of the $\mathrm{G}, 4$. This is just one of several charts that Rosman produced, and is the outcome of many hours of careful experimentation, showing the detail of his workings. The chart is indicative of the intimate relationship performers have with their instruments: Rosman's fingering charts do more than supply Johnson with static information about the execution of pitches; they share with him a sense of Rosman's embodied perception of the instrument. But how did they function within the creative process?

Once Johnson had established that the dyad was relatively responsive and could be securely executed (without requiring a gradual fading-in) he used it frequently in the piece. It first appears in bar 24 (Figure 3).

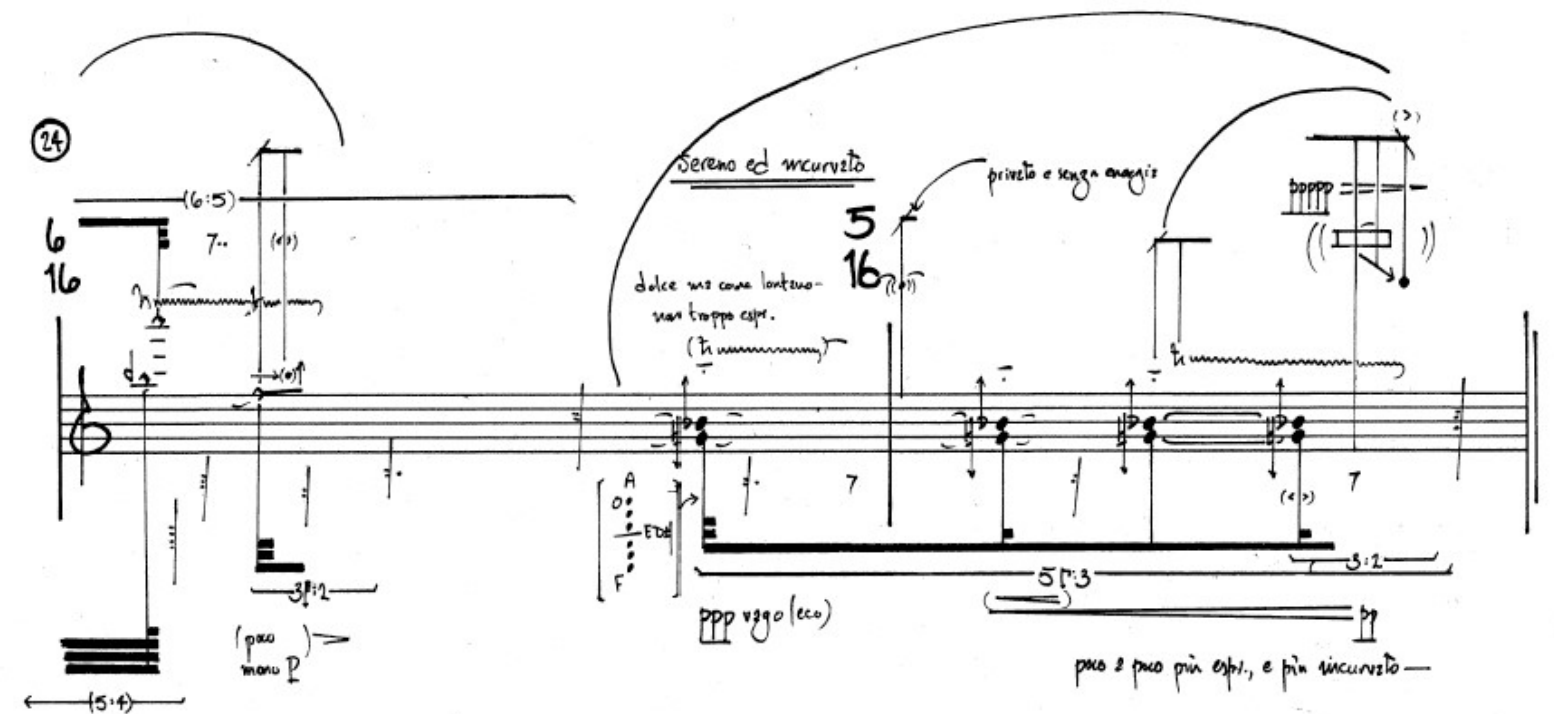

Figure 3. First appearance of lowered $\mathrm{G} \sharp 4$ / raised B/4 dyad (b. 24) (Johnson, 2015, p. 4).

Reproduced by permission of E. Johnson.

The multiphonic was also chosen for its harmonic function, since it fitted within one of the work's primary pitch structures. It became, in Johnson's words, 'a main "signal" of the piece', occurring throughout 'in a generally canonic/self-referential way' (E. Johnson, unpublished email correspondence to C. Rosman and E. Payne, 20 May 2015). In this instance, there is a gradual transition from the hesitant beginnings evidenced in the first 
workshop - where Johnson's prior conceptions appeared to distance him from investigating multiphonics in a significant manner - towards a point nearly a year later where the technique became a compositionally important element of the piece.

\section{'I almost feel like writing “I woz ere”...'}

By contrast to the previous example, the following discussion shows how, at a more advanced stage of the collaboration, Johnson and Rosman were working in a much less exploratory and more direct manner. In April 2015 Johnson emailed Rosman with a score fragment, on which he had marked up two places where he intended to include a multiphonic on $\mathrm{A} \ddagger 4$ (see Figure 4).

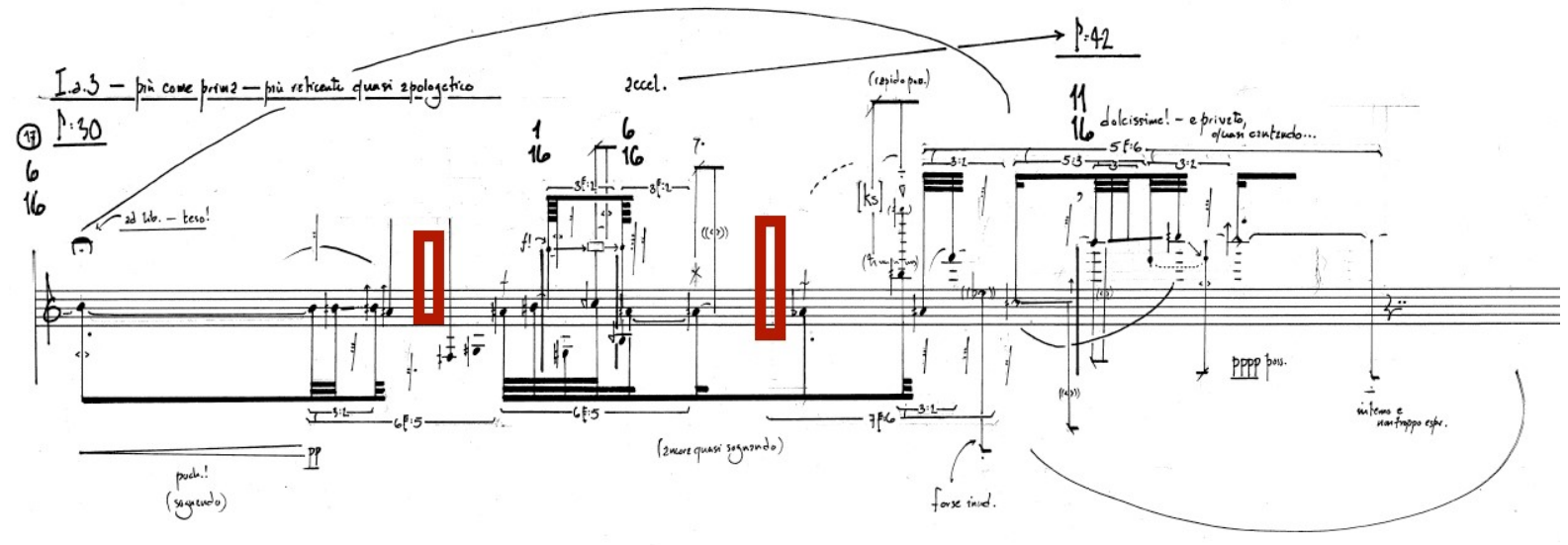

Figure 4. Score fragment with multiphonic 'voids' (bb. 17-18) (11 April 2015). Reproduced by permission of E. Johnson.

Below is an extract from Johnson's email:

I've attached the current state of the passage for which I'm looking for multiphonic(s), with the holes for which they are destined outlined in an eyecatching red. The first would ideally be coincident with the end of a small lipgliss down from the preceding $\mathrm{A} \sharp \uparrow 4$, and the second at the end of a tie from the preceding $\mathrm{A} \ddagger 4$.

I don't remember what I told you before about the criteria but in an ideal world they would be more or less as follows:

(1) not TOO nice - some crunch/energy is good - but not hugely honky either

(2) as secure/immediate an onset as possible 
(3) dynamic $p$-ppp or so, although if they have to punch out a bit they can (and a slight cresc. into them isn't impossible either)

(4) ideally they wouldn't be the same; not sure at the mo which one I'd want to be crunchier but my instinct at the moment is the first, if it matters. If there's only one that works, and it works both places, repeating is not the end of the world either.

If I can't have it all, let me know and I'll prioritize as needed. If it can't be done at all, I'll just have to think of something else. (E. Johnson, unpublished email correspondence to C. Rosman and E. Payne, 11 April 2015, 03:50)

Johnson's very specific request suggests that by this stage he had gained a greater degree of familiarity with the technical possibilities of the basset, and had a much more developed sense of his compositional intentions. Rosman replied promptly, sending Johnson four possibilities, with an accompanying fingering chart (Figure 5) and recording (Audio example

$\underline{2})$.

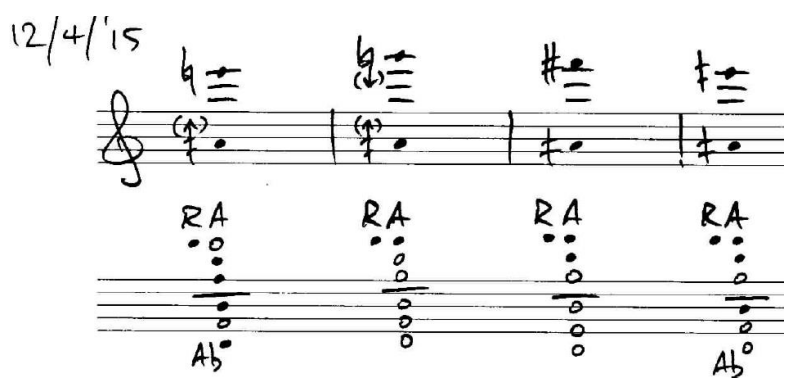

Figure 5. Rosman’s fingering chart for multiphonics on A $\$$ (12 April 2015). Reproduced by

permission of C. Rosman.

The subsequent email exchange proceeded as follows:

EJ: These are actually perfect, many thanks! The middle two I think will inhabit those red rectangles in some order or other... speaking of which, are the middle two straightforwardly trillable (or more precisely mordentable) by means of - would that be L2?

CR: You learn fast! Yes, indeed that is and indeed they are. There are also various little colour trills possible, especially with the R4 A, key. The fourth one can be quite a pure twelfth although that's not how it came out on the recording if I remember right.

EJ: The results as they currently stand are attached. [Figure 6] Thanks for filling a pair of holes that had been in the pencil sketches for weeks! 
CR: Hurrah! I almost feel like writing 'I woz ere'...

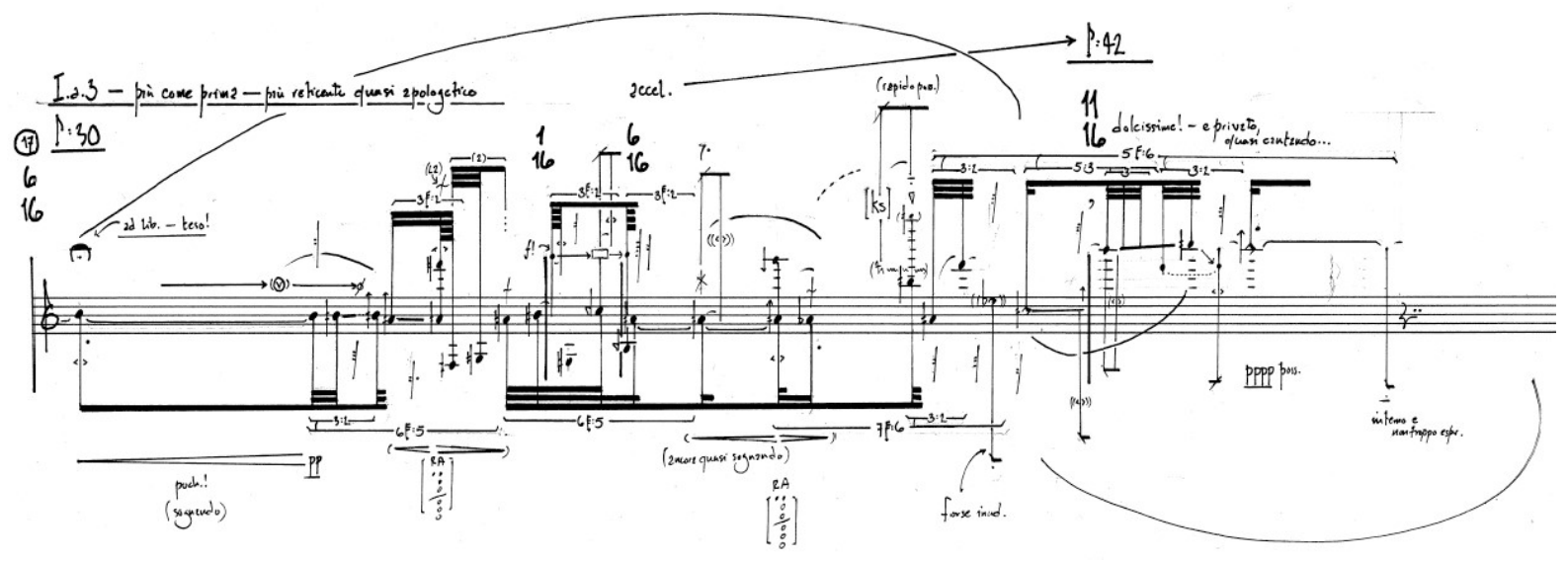

Figure 6. Score fragment with notated multiphonics (bb. 17-18) (12 April 2015). Reproduced by permission of E. Johnson.

Taking place over the course of just a single day, the interaction here is more direct than that of the previous example, with Rosman literally 'filling in the gaps' of the musical material. Whereas in the previous scenario there was a sense of the musicians investigating possibilities in a fluid and undefined manner that gradually animated Johnson's approach to multiphonics, in this case a specific compositional decision was made from a limited number of options. There is a sense of mutual satisfaction in the tone of their correspondence, and Rosman's final comment articulates a feeling of ownership over this specific material. Clearly, the nature of email communication necessitates a more economical way of working than when having the time to explore possibilities in a face-to-face workshop environment. Yet there is also a sense that the collaborative balance has shifted, with Johnson and Rosman apparently fitting within the more traditional roles of composer and performer: Johnson requiring Rosman's expertise on a purely technical level, to address a particular compositional 'problem'. ${ }^{9}$ It is also important to note that this particular episode was a consequence of the earlier workshop phase, acknowledged by Rosman's compliment, 'You 
learn fast'. It is unlikely that the musicians would have progressed to such an efficient manner of working had they not had the opportunity to investigate the instrumental possibilities so intensely in their previous meetings.

\section{The thwocking effect}

By contrast to the examples discussed so far, some of the techniques that are employed in 'indolentiae ars' were discovered almost by accident, rather than being the outcome of a traceable process of development. The term '(controlled) accident' is employed by Fitch and Heyde (2007, p. 92) to denote the unexpected discoveries that arose during their workshops, although the strategies that led to their discovery were intentional. This process is similar to the working method employed by Johnson and Rosman: during their workshops they worked through a list of techniques relatively systematically, paying close attention to sounds and the actions that gave rise to them. The intention to celebrate the unstable and chaotic qualities of performance is also evident in Liza Lim's Invisibility (2009) for solo cello. Lim (2013) describes employing a 'guiro' bow (where the bow hair is wrapped around the body of the bow to create an irregular surface) in order to produce 'accelerations, glitches and slippages as the undulating surface of alternating hair and wood passes over a string' (Lim, 2013). The practices described by both Fitch and Heyde, and Lim, focus on the instrumentality of performance: foregrounding the materiality of a specific instrument in the hands of the performer. In the present collaboration, however, rather than preparing the instrument to encourage unexpected performance outcomes, the liminal sounds were an outcome of three interrelated circumstances: the particularly unstable ergonomic properties of the basset clarinet; Rosman's relatively raw relationship to it during the earlier stages of the project; and Johnson's compositional concern to experiment with the physicality of sound production. Thus, this third section concentrates on an 'accidental' playing technique and its incorporation into the sound world of 'indolentiae ars': nicknamed 'thwocking' by Johnson. 
Video example 2 shows an episode from the first workshop where the somewhat volatile relationship between Rosman's technique and his instrument became a source of creative exploration. The clip opens with the musicians discussing specific cross-fingerings that are required by the instrument's design, their prominence in Mozart's Quintet, and the implications of the technique for performance (Rosman describes the placement of the hole on the bore of the instrument: 'The hole's in the wrong place: that's too high, that's too low, so I need something in the middle', with Johnson responding that the cross-fingering is 'a compromise, fundamentally'). This exchange is followed by a short period of exploration and discussion of the role of B flat and its employment at significant or 'pivotal' moments in the piece. Listening to Rosman, Johnson remarks on the liminal noises caused by the transition between alternating fingers covering and uncovering the open holes: 'The changing of those fingers is making a little bit of a hiccup.' While Rosman responds that these sounds generally tend to be avoided in classical clarinet technique, Johnson comments on their appeal for him. During an interview after the meeting, Johnson expressed his enthusiasm for this unexpected sound:

The sound of the fingers opening and closing - those little pops that you get that's the sort of thing that never would have occurred to me sitting at home that that would happen. [...] This is completely new thing for me; it's something I'm really excited about. (E. Johnson, unpublished interview, 6 April 2014)

It is significant to note that, as Rosman remarked in the video, the transitional 'hiccups' that piqued Johnson's curiosity tend to be avoided in classical clarinet performance practice. In the third workshop (Audio example 3) these sounds were pursued further, with Rosman exploring the sonic outcome of executing tremolos of increasingly wide intervals, which required more fingers to move simultaneously. The musicians' exchange is guided by their mutual close attention to Rosman's embodied relationship to the instrument and the variations in the resultant sounds, with Johnson expressing a preference for particular 
combinations of notes ('The ones with all three left-hand fingers, that tremolo is really nice. [...] There's a minor sixth that was nice') and diagnosing ways of executing the sounds, noting the combinations of fingers that generate the strongest sound ('So it's really the righthand trills that have the thwocking effect.'). As Johnson comments at the outset of the episode, he could have sought out various sonic effects by consulting the fingering charts that Rosman produced and sent to him (as in the 'I woz ere' example), but their moment-tomoment interactions during the workshop afforded a more reflexive investigation of the possibilities. Rosman's relationship to his instrument offered a particular kind of unstable state that Johnson was curious about, and in response to Johnson's questioning, Rosman was able to manipulate the 'cracks' and 'edges' of the technique in such a way that Johnson found aesthetically interesting. The exchange concludes with the pair laughing over Johnson's use of the term 'thwocking', with Rosman joking, 'I expect to see that in the performance notes' and Johnson playfully elaborating the term into an Italian expressive direction ('Thwockando! Quasi thwockando, ma espressivo!').

Audio example 3 illustrates the importance of an instrument offering pleasure in itself. Johnson and Rosman were exploring the resistances and instabilities of the instrument in a systematic manner, but there is also a sense of them simply playing (in the recreational sense of the word) with this somewhat strange instrument to see what kind of sounds it can make. Looking beyond the light-hearted situation, however, the joke is indicative of the wider aesthetic and cultural forces that permeate their collaboration. By invoking a conventional musical term humorously, Johnson (who himself uses Italian performance directions extensively in his work) is on one level perhaps making light of their situation by referring to his own compositional rhetoric in a somewhat self-deprecating manner; more broadly, however, the joke positions their interaction within a specific cultural and historical ecology (broadly speaking, contemporary Western ‘concert' music). Drawing on Byron Dueck’s 
(2013a; 2013b) work on musical 'intimacies' and 'imaginaries' (or 'publics'), Clarke et al. (2016) have characterised the dialectic between the immediate and present interactions between musicians and the wider ecology that they evoke as 'Inside/outside the room', whereby 'dialogue that references materials, persons and practices outside the room, as well as the immediate references to these things in the room, brings out the mesh-like qualities of creativity as distributed over time, materials (notations, images, instruments), and people' (2016, p. 143). Johnson knows that Rosman will appreciate his 'thwockando' joke because they share the same frames of reference; his remark thus simultaneously intersects their intimate relationship and the 'broader imagined sphere' (Dueck, 2013a, p. 100) of contemporary Western concert music which they inhabit.

In this instance an unforeseen quality of Rosman's technical relationship to the instrument was employed in a significant manner in the eventual piece. Johnson's performance notes in the final score reflect his enthusiasm for the sound, instructing the performer that trills and tremolos should be executed

[...] with fingering 'noise' (in particular, perceptible timbral disruption from the opening and closing of the open holes) encouraged (i.e. the secondary pitch should not necessarily be one as close as possible to the main pitch in terms of fingering action. (Johnson, 2015, p. iii; original emphasis)

The thwocking effect celebrates the material qualities of the instrument and the physical energies employed in its production. Paradoxically, it is possible that if Rosman had possessed a more 'developed' technique at this stage, these transitional sounds might have been completely eradicated from his playing, and would never have appeared in the piece. However, it is also important to acknowledge Johnson's role in these events. It is his interest in performative ambiguity that focussed his attention on these particular sounds, leading him to encourage Rosman to pursue them further during the workshops. Despite its apparent liminality then, the thwocking effect was embedded in an entanglement of relations including 
the cultural and historical resonances of the basset clarinet and its physical idiosyncrasies, the tactility of Rosman's fingers on the instrument's open holes, the musicians' personal relationship and their mutual aesthetic concerns, and the sustained periods of experimentation afforded by their workshops.

\section{Conclusions}

Johnson's dedication is certainly justified in acknowledging the crucial role that Rosman played in 'indolentiae ars', to the extent that it is difficult to imagine the piece being performed by another player. Analysis of the development of compositional material renders visible the co-constitutive and relational nature of that collaborative work. In the workshop settings the musicians actively explored the possibilities afforded by the basset clarinet, guided by attentive engagement with Rosman's bodily capacities and their changing relationship to the instrument. Johnson's compositional rhetoric was realised in almost symbiotic collaboration with Rosman, through processes of gradual development and experimentation such as those that resulted in the multiphonics; efficiency ('I woz ere'); and through 'accidents', where a transitional aspect of Rosman's technique was encountered, embellished, and then incorporated into a performance practice - the thwocking effect.

It is important to acknowledge that I have focussed solely on the production stage of Johnson and Rosman's creative collaboration: the process of preparing and performing the piece inevitably raised other possibilities and questions that are beyond the scope of this article. This point raises a broader issue: the importance of focussing on relationships and processes over products or outcomes. A number of elements played an integral role in the collaborative process, but did not result in material outcomes in the score. This is particularly apparent in the influence of Mozart which, although certainly present in Johnson and Rosman's discussions, is evident only in an opaque or concealed manner in the eventual score. ${ }^{10}$ Mozart played a significant role during the workshops, as part of an aesthetic 
discourse that facilitated exploration of performance practices, and in terms of Rosman's embodied relationship to the instrument. Thus the historical lineage of the basset clarinet is addressed implicitly - it is one of several avenues through which performance possibilities are explored, rather than a source of 'concrete' sonic material.

A crucial factor in the collaboration was the musicians' personal relationship and its intersections with their shared professional spheres and frames of reference. The assumptions that underpin their conversations, practices, and the aesthetic discourses that motivate them are informed by and respond to the institutional and professional traditions which they inhabit, but they are also facilitated by an existing level of trust and mutual respect that had been established over a number of years before the outset of this project. In fact, as Johnson expressed during interview, the very motivation behind the commission lay in their shared interests and aesthetic concerns. What are the implications of this familiarity for the dynamics of the collaboration? It at least partially eliminates the anxieties of working with a collaborator with whom one has a limited prior relationship. For instance, the need to demonstrate one's competence and craft (see Clarke et al., 2016, pp. 140-142) in order to reach a level of shared understanding was less of a concern in this scenario. Their trust was conducive to risk-taking, which was particularly beneficial in light of the unfamiliar instrumental and technical territory in which they were working.

If this observation sounds overly positive and confirming, a final point inflects the potential 'illusions' of collaborative equality: although this commission certainly blurs the boundaries of creative ownership, with Johnson and Rosman's workshops and correspondence playing a crucial phase in the genesis of the piece, it would be wrong to overemphasise the collaborative nature of the project. Not all of the developments in the piece can be ascribed to the shared input of both performer and composer. Johnson was clearly responsible for a number of decisions, and undertook a significant amount of 'private' 
work independently of his interactions with Rosman, the nature of which has not been explored in great detail here. Moreover, as was evidenced in the 'I woz ere' discussion, sometimes Rosman's role was to provide Johnson with material without having any input into how it might be employed - as Johnson put it, he was literally 'filling a pair of holes'. This is not to deny the evidently distributed and interactive nature of their work; and any case, in no way did Rosman appear disenfranchised by this manner of working (indeed, his 'I woz ere' comment appears to express quite the opposite). But it is important to recognise the more directive 'filling holes' approach as a valid manifestation of creative activity. As I have suggested, a wide variety of working practices are manifest within shared work, some more obviously 'collaborative' than others. The musicians demonstrated various working processes, with some exchanges functioning more directly, while others were more expansive and emergent in character, in addition to the 'private' work that Johnson undertook in creating the score. These apparent paradoxes suggest that the concept of collaboration could benefit from being broadened to allow for the sometimes more distributed character of creative work. It is important to acknowledge the limits of the term in capturing the variety of interplay and exchange that can occur. Nevertheless, while the three examples of the development of musical material discussed in this article represent particular dimensions of 'indolentiae ars', they show quite subtly how musical instruments can be understood as, in Hutchins' words, 'repositories' of different kinds of knowledge and practices that are animated through collaboration. It is arguably the case that all musical works are contingent on a particular combination of the performer's body, skills, and instrument; and 'indolentiae ars' demonstrates this reality particularly vividly. As musicians work together, their interactions are enmeshed, both with the 'concrete' material tools of their environment and with the implicit but no less significant aspects of their craft - the embodied and tacit processes of performance. 


\section{Acknowledgements}

I am grateful to Evan Johnson and Carl Rosman for their generosity and goodwill throughout the project. I wish to thank Laura Anderson, Eric Clarke, and Philip Thomas for their helpful comments on earlier versions of this paper. 


\section{Funding}

This research was undertaken at the University of Oxford, with financial support from St. Peter's College, the Faculty of Music, and the Royal Musical Association. 


\section{Notes}

1. Rosman has played a number of Johnson's ensemble pieces before as a member of musikFabrik; he also gave the premiere of $A$ general interrupter to ongoing activity for solo voice (2011), and was the dedicatee of Apostrophe 1 (All communication is a form of complaint) for two bass clarinets (2008). However, this is the first time that the musicians worked closely together on a solo work.

2. The aria 'Parto, Parto' in Mozart's La Clemenza di Tito K. 621 (1791) includes a part for basset clarinet in the key of B flat, but the Concerto and Quintet are the only two extant solo works. It is reasonable to argue that historical basset clarinets are made today with the sole intention of performing the Mozart repertoire.

3. In the specific context of this paper, the term 'workshop' denotes an environment (either faceto-face or online) of artistic work, trial, and development in which composers and/or performers interact during a work's compositional stage. As such, I make a distinction between the activities of 'workshopping' and 'rehearsing', in contrast to the definition proposed by Zubin Kanga (2014) who includes rehearsing within the definition of workshop. I do not mean to suggest that the musical 'work' is a fixed and final object by the rehearsal stage, but my understanding is based on the language employed by the participants of my research. As one musician put it, "The word "workshop" can mean about a million different things. Every single so-called “workshop" I've ever attended has been an utterly different entity' (Participant interview, cited in Payne, 2015, p. 5).

4. Linda Kaastra $(2008 ; 2011)$ has investigated distributed cognition in ensemble coordination, but her work is more concerned with processes of live music-making.

5. The following account is not intended to be an exhaustive investigation of the basset clarinet, but aims to attend to the properties that were pertinent to this particular instrument within the context of the collaboration. For detailed organological discussions of the eighteenth-century basset clarinet, see Hoeprich (2008) and Shackleton (1995). 
6. Cross-, or 'fork' fingerings, are fingering configurations where the fingers are raised and lowered out of serial order, a technique that was eradicated with the development of the Boehm key system. See Lawson (1995; 2000).

7. Johnson's Largo Calligrafico / 'Patientiam' for baritone saxophone (2012) contains a single brief dyad.

8. Rosman's first sketch corresponds to a five-key historical clarinet, with the subsequent diagrams relating to the nine-key basset clarinet.

9. Hayden and Windsor categorise this manner of working as 'interactive' (2007, p. 33).

10. Johnson described the triadic character of the opening passage of the piece as 'a sort of wink at the characteristic gestures of the Mozart Concerto'; and that certain pitch structures were derived from transformations of the opening phrase of the Mozart Clarinet Quintet (E. Johnson, unpublished email correspondence to C. Rosman and E. Payne, 20 May 2015). This subject is explored in further detail in Payne (2015, pp. 215-222). 


\section{References}

Appadurai, A. (Ed.). (1988). The social life of things: Commodities in cultural perspective. Cambridge, UK: Cambridge University Press.

Archbold, P. (2011). Climbing a mountain: Brian Ferneyhough's Sixth String Quartet in rehearsal and in performance [Videorecording]. London, UK: Optic Nerve.

Barrett, M. S., Ford, A., Murphy, P., Pollett, P., Sellars, E., \& Viney, L. (2014). The Scattering of Light: Shared insights into the collaborative and cooperative processes that underpin the development and performance of a commissioned work. In M. S. Barrett (Ed.), Collaborative creative thought and practice in music (pp. 17-31). Farnham, UK: Ashgate.

Bates, E. (2012). The social life of musical instruments. Ethnomusicology, 56, 363-395.

Bayley, A. (2010). Multiple takes: Using recordings to document creative process. In A. Bayley (Ed.), Recorded music: Performance, culture and technology (pp. 206-224). Cambridge, UK: Cambridge University Press.

Bayley, A. (2011). Ethnographic research into contemporary string quartet rehearsal. Ethnomusicology Forum, 20, 385-411.

Bayley, A., \& Clarke, M. (2009). Analytical representations of creative processes in Michael Finnissy's Second String Quartet. Journal of Interdisciplinary Music Studies, 3(1-2), $139-157$.

Bayley, A., \& Clarke, M. (2011). Evolution and collaboration: The composition, rehearsal and performance of Michael Finnissy’s Second String Quartet using Max/MSP software. Lancaster, UK: PALATINE.

Clarke, E. F., Cook, N., Harrison, B., \& Thomas, P. (2005). Interpretation and performance in Bryn Harrison's être-temps. Musicae Scientiae, 9, 31-74. 
Clarke, E. F., Doffman, M., \& Lim, L. (2013). Distributed creativity and ecological dynamics: A case study of Liza Lim's Tongue of the Invisible. Music and Letters, 94, $628-663$.

Clarke, E. F., Doffman, M., \& Timmers, R. (2016). Creativity, collaboration and development in Jeremy Thurlow's Ouija for Peter Sheppard Skærved. Journal of the Royal Musical Association, 141, 113-165.

de Souza, J. (2013). Musical instruments, bodies, and cognition (Unpublished doctoral thesis), University of Chicago, IL.

Donin, N., \& Féron, F.-X. (2012). Tracking the composer's cognition in the course of a creative process: Stefano Gervasoni and the beginning of Gramigna. Musicae Scientiae, 16, 262-285.

Donin, N., \& Theureau, J. (2007). Theoretical and methodological issues related to long term creative cognition: The case of musical composition. Cognition, Technology \& Work, 9, 233-251.

Dueck, B. (2013a). Jazz endings, aesthetic discourse, and musical publics. Black Music Research Journal, 33, 91-115.

Dueck, B. (2013b). Musical intimacies and indigenous imaginaries: Aboriginal music and dance in public performance. New York, NY: Oxford University Press.

Fitch, F., \& Heyde, N. (2007). Recercar: The collaborative process as invention. TwentiethCentury Music, 4, 71-95.

Hayden, S., \& Windsor, L. (2007). Collaboration and the composer: Case studies from the end of the $20^{\text {th }}$ century. Tempo, 61, 28-39.

Hoeprich, E. (2008). The clarinet. New Haven, CT; London, UK: Yale University Press. 
Hooper, M. (2012). The start of performance, or, does collaboration matter? Tempo, 66, 2636.

Hooper, M. (2013). The well-tempered oboe and the tradition of innovation. Musical Times, $154,67-89$.

Hutchins, E. (1995). Cognition in the wild. Cambridge, MA; London: MIT Press.

Ingold, T. (2011). Being alive: Essays on movement, knowledge and description. Abingdon, UK: Routledge.

Johnson, E. (2014). Biography. Evan Johnson: Composer. Retrieved from http://www.evanjohnson.info/biography/

Johnson, E. (2015). 'indolentiae ars', a medium to be kept [self-published score].

Kaastra, L. (2008). Systematic approaches to the study of cognition in western art music performance (Unpublished doctoral thesis), University of British Columbia.

Kaastra, L. (2011). Annotation and the coordination of cognitive processes in western art music performance. In A. Williamon, D. Edwards, \& L. Bartel (Eds.), Proceedings of the International Symposium on Performance Science 2011 (pp. 675-680). Utrecht: European Association of Conservatoires.

Kanga, Z. (2014). Inside the collaborative process: Realising new works for solo piano. (Unpublished doctoral thesis), Royal Academy of Music, London, UK.

Lachenmann, H. (1996). Musik als existentielle Erfahrung. (J. Häusler, Ed.). Wiesbaden: Breitkopf \& Härtel.

Lawson, C. (1995). Playing historical clarinets. In C. Lawson (Ed.), The Cambridge companion to the clarinet (pp. 134-149). Cambridge, UK: Cambridge University Press. 
Lawson, C. (2000). The early clarinet: A practical guide. Cambridge, UK: Cambridge University Press.

Lim, L. (2013, April). A mycelial model for understanding distributed creativity:

Collaborative partnership in the making of Axis Mundi (2013) for solo bassoon. Paper presented at CMPCP Performance Studies Network International Conference, University of Cambridge, UK.

Merrick, L. (2009). Collaboration between composers and performers: British clarinet concertos 1990-2004. Saarbrücken: VDM Verlag.

Östersjö, S. (2008). SHUT UP 'N'PLAY! Negotiating the musical work (Unpublished doctoral thesis), Lund University, Sweden.

Payne, E. (2015). The creative process in performance: A study of clarinettists. (Unpublished doctoral thesis), University of Oxford, UK.

Poulin, P. (1991). A report on new information regarding Stadler's concert tour of Europe and two early examples of the basset clarinet. Mozart-Jahrbuch, 946-955.

Redgate, C. (2007). Re-inventing the oboe. Contemporary Music Review, 26, 179-188.

Roche, H. (2011). Dialogue and collaboration in the creation of new works for clarinet. (Unpublished doctoral thesis). University of Huddersfield, UK.

Roe, P. (2007). A phenomenology of collaboration in contemporary composition and performance. (Unpublished doctoral thesis), University of York, Heslington, UK.

Seddon, F. (2004). Empathetic creativity: The product of empathetic attunement. In D. Miell \& K. Littleton (Eds.), Collaborative creativity: Contemporary perspectives (pp. 6578). London, UK: Free Association Books. 
Seddon, F., \& Biasutti, M. (2009). Modes of communication between members of a string quartet. Small Group Research, 40, 115-137.

Shackleton, N. (1995). The development of the clarinet. In C. Lawson (Ed.), The Cambridge companion to the clarinet (pp. 16-37). Cambridge, UK: Cambridge University Press. van der Poel, P. (2014). Lotz-clarinets. Peter van der Poel houten blaasinstrumenten. Retrieved from http://www.petervanderpoel.nl/klarinetten/lotzE.html 